\title{
Fluorine-Doped Hard Carbon as the Advanced Performance Anode Material of Sodium-Ion Batteries
}

\author{
Lingchen Kong ${ }^{1} \cdot \mathrm{Yu} \mathrm{Li}^{1} \cdot$ Wei Feng ${ }^{1}$
}

Received: 25 November 2021 / Revised: 28 November 2021 / Accepted: 29 November 2021 / Published online: 29 January 2022

(c) The Author(s) 2022

\begin{abstract}
F-doping hard carbon (F-HC) was synthesized through a mild fluorination at temperature at relative low temperature as the potential anode for sodium-ion batteries (SIBs). The F-doping treatment to HC expands interlayer distance and creates some defects in the graphitic framework, which has the ability to improve $\mathrm{Na}^{+}$storage capability through the intercalation and pore-filling process a simultaneously. In addition, the electrically conductive semi-ionic $\mathrm{C}-\mathrm{F}$ bond in $\mathrm{F}-\mathrm{HC}$ that can be adjusted by the fluorination temperature facilitates electron transport throughout the electrode. Therefore, F-HC exhibits higher specific capability and better cycling stability than pristine HC. Particularly, F-HC fluorinated at $100{ }^{\circ} \mathrm{C}(\mathrm{F}-\mathrm{HC} 100)$ delivers the reversible capability of $343 \mathrm{mAh} / \mathrm{g}$ at $50 \mathrm{mAh} / \mathrm{g}$, with the Coulombic efficiency of $78.13 \%$, and the capacity retention remains as $95.81 \%$ after 100 cycles. Moreover, the specific capacity of $\mathrm{F}-\mathrm{HC} 100$ returns to $340 \mathrm{mAh} / \mathrm{g}$ after the rate capability test demonstrates its stability even at high current density. The enhanced specific capacity of F-HC, especially at low-voltage region, has the great potential as the anode of SIBs with high energy density.
\end{abstract}

Keywords Hard carbon $\cdot$ Fluorine doping $\cdot$ Semi-ionic C-F bond $\cdot$ Sodium-ion batteries

\section{Introduction}

Lithium-ion batteries (LIBs) have become widely used electrochemical energy storage system because they have many advantages, such as high reversible capacity and excellent rate stability $[1,2]$. However, with the increasing demand for large-scale applications, such as portable electronic devices and electric vehicles, the high cost of lithium resources and limited lithium reserves have emerged as a public concern; therefore, advanced electrochemical energy storage devices have been explored as alternatives to LIBs [3, 4].

Among various alternatives, sodium-ion batteries (SIBs) are considered ideal candidates because of their abundant reserve, uniform and wide distribution, and a similar working mechanism to LIBs [5, 6]. Although LIBs have been widely applied, a thermodynamically unfavorable $\mathrm{Na}$-graphite compound revealed by the positive binding energy between graphite and $\mathrm{Na}$ impedes the application of graphite as a SIB anode [7, 8]. As such, studies have investigated

Wei Feng

weifeng@tju.edu.cn

1 School of Materials Science and Engineering, Tianjin University, Tianjin 300072, China various SIB anode materials, including alloys, metal oxides, and organic compounds [9-11]. However, the poor cycling stability caused by large volume expansion/shrinkage during a discharge/charge process limits practical applications; furthermore, they have a relatively high cost and complex synthesis process. Therefore, highly stable and low-cost SIB anode materials should be developed.

Among various carbon-based anode materials, hard carbon (HC) has been demonstrated as the most promising SIB anode because of advantages such as extensive starting source, simple fabrication, and excellent cycling stability [12]. HC is usually derived from polymer pyrolysis at ultrahigh temperatures $\left(>3000{ }^{\circ} \mathrm{C}\right)$. It has been widely explored because of its large interlayer space and disordered structures. It is nongraphitizable, and its molecular-level structure is different from the long-range ordered layer structure of graphite [13]. Randomly oriented and short-range ordered graphitic domains, microvoids and nanovoids, and amorphous regions provide various locations for $\mathrm{Na}^{+}$storage; consequently, a theoretically high reversible specific capacity of $580 \mathrm{mAh} / \mathrm{g}$ is obtained [14]. The insertion/extraction mechanism of $\mathrm{Na}^{+}$in $\mathrm{HC}$ is contributed by $\mathrm{Na}^{+}$intercalation in small graphitic layers and pore filling in micropores, which are represented by a low-voltage plateau region and 
a sloping voltage region, respectively [15-17]. The specific capacity of $\mathrm{HC}$ is lower than the theoretical value. Therefore, the specific capacity of $\mathrm{HC}$ should be improved by increasing surface areas, enlarging interlayer spaces, introducing defective structures, tuning pore size distribution, and other techniques.

Various methods have been developed to regulate the structural properties of HC. One of the most promising routes is heteroatom doping; in this route, hetero-atoms are doped into a graphene framework to adjust interlayer distances and increase active sites, thereby extending the plateau capacity and increasing the sloping capacity, respectively $[18,19]$. For example, the interlayer spacing of HC is reduced by $\mathrm{P}$ or $\mathrm{S}$ doping; consequently, the reversible capacity in a low-voltage region is enhanced, and the abundant defects generated by $\mathrm{P}$ doping increase the sloping sodiation capacity [20]. Structural defects form through N doping, and this phenomenon helps achieve a high specific capacity and facilitates $\mathrm{Na}^{+}$diffusion kinetics [21].

Another element doping method is F doping, which is a unique approach to enhance the electrochemical activity and cycling stability of carbonaceous electrodes for energy storage devices; this improvement is attributed to the charge polarization between $\mathrm{C}$ and $\mathrm{F}$ and the strongest $\mathrm{C}-\mathrm{F}$ bond among all single covalent bonds [22]. Through $\mathrm{F}$ doping, the interlayer spacing can be enlarged, and a defective structure can be created in a carbonaceous framework; for example, F-doped carbon particles derived from lotus petioles with an interlayer distance of $\sim 0.4 \mathrm{~nm}$ yield a specific capacity of $228 \mathrm{mAh} / \mathrm{g}$ with excellent capacity retention [23]. At $50 \mathrm{~mA} / \mathrm{g}$, fluorocarbon $\left(\mathrm{C}_{x} \mathrm{~F}_{y}\right)$ obtained through the pyrolysis of polyvinylidene fluoride (PVDF) exhibits a specific capacity of $269 \mathrm{mAh} / \mathrm{g}$, which is dependent on F-doping content [24]. Similarly, the pyrolysis of polytetrafluoroethylene produces F-doped carbon, whose specific capacity further increases with $\mathrm{N}$ doping and activation by $\mathrm{KOH}$ [25]. The utilization of $\mathrm{F}$ radicals generated by hydrothermal synthesis [26] and plasma [27] is also an effective route to produce F-doped carbonaceous SIB anodes by using an F-containing polymer as a precursor. Thus, the formed semi-ionic $\mathrm{C}-\mathrm{F}$ bond accelerates the charge transfer of electrodes.

$\mathrm{F}$ doping can improve the electrochemical performance of carbonaceous SIB anodes, but conventional methods of $\mathrm{F}$ doping are inefficient, and the F-doping content in a carbonaceous matrix is usually less than 10 at.\%. Nevertheless, fluorination with $\mathrm{F}_{2}$ gas at high temperatures is the most effective and practical approach to form the C-F bond on a carbonaceous matrix; therefore, our group synthesized fluorinated $\mathrm{HC}(\mathrm{F}-\mathrm{HC})$ by using $\mathrm{F}_{2}$ gas and obtained a material with superior electrochemical performance to commercial fluorinated graphite [28].

In this work, $\mathrm{HC}$ was further modified with $\mathrm{F}_{2}$ gas at a relatively low temperature $\left(\leq 150{ }^{\circ} \mathrm{C}\right)$ to tune its electrochemical performance as a SIB anode. The F doping degree and the type of the $\mathrm{C}-\mathrm{F}$ bond were adjusted in terms of fluorination temperature. The resultant $\mathrm{F}-\mathrm{HC}$ with a semiionic $\mathrm{C}-\mathrm{F}$ bond, desirable $\mathrm{F}$ doping degree, and enlarged interlayer distance yielded a higher specific capacity and better cycling stability than pristine HC. Therefore, F doping could be a feasible strategy to improve the electrochemical performance of $\mathrm{F}-\mathrm{HC}$ for energy storage devices.

\section{Experimental}

\section{Material Preparation}

HC was directly purchased from Japan Kuraray Co., Ltd. $\mathrm{F}-\mathrm{HC}$ was synthesized through gas-phase fluorination. A given amount of $500 \mathrm{mg} \mathrm{HC}$ was initially placed in a Monel alloy plate and then on a stove for the next $\mathrm{F}$ doping. The $\mathrm{F}_{2} /$ $\mathrm{N}_{2}$ mixed gas ( $20 \% \mathrm{~F}_{2}$ volume ratio) was introduced into the reacting stove, and the temperature was maintained at $50{ }^{\circ} \mathrm{C}$, $100{ }^{\circ} \mathrm{C}$, and $150^{\circ} \mathrm{C}$ for $4 \mathrm{~h}$, respectively. After the reaction, pure $\mathrm{N}_{2}$ gas was injected into the reactor to remove residual $\mathrm{F}_{2}$, and the stove was cooled down to room temperature. Lastly, F-HC products were collected and labeled F-HC50, $\mathrm{F}-\mathrm{HC} 100$, and $\mathrm{F}-\mathrm{HC} 150$, respectively.

\section{Characterizations}

Morphological characteristics were observed under a fieldemission scanning electron microscope (FESEM; Hitachi S-4800) and a field-emission transmission electron microscope (FETEM; S-4800, Hitachi). Raman spectroscopy was acquired by using DXR Microscope Thermo Electron at laser excitation of $532 \mathrm{~nm}$. X-ray diffraction (XRD) patterns were obtained on Rigaku D/max- 25 with $\mathrm{Cu} \mathrm{K} \alpha$ radiation), and diffraction data were recorded at $2 \theta$ angles from $10^{\circ}$ to $90^{\circ}$. X-ray photoelectron spectroscopy (XPS) was conducted using a PerkinElmer PHI 3056 with an $\mathrm{Al}$ anode source operated at $15 \mathrm{kV}$ to analyze the chemical composition of the surface of the materials. $\mathrm{N}_{2}$ adsorption/desorption characteristics were measured using an Autosorb-iQ2-MP (Quantachrome, the USA) at $-196.15^{\circ} \mathrm{C}$ after the sample was degassed at $300{ }^{\circ} \mathrm{C}$ until the pressure reached $266 \mathrm{~Pa}$ to obtain the specific surface areas and pore volume of the samples.

\section{Electrochemical Measurements}

The electrochemical performance was evaluated using CR2032 coin cells. F-HC or HC powder was mixed with Super-P and PVDF with a weight ratio of 80:10:10 in $\mathrm{N}$-methyl-2-pyrrolidone using a mortar and pestle. The homogeneous slurry was pasted onto $\mathrm{Cu}$ foil (99.9\%, 
Goodfellow) and then dried in a vacuum oven at $120^{\circ} \mathrm{C}$ for $10 \mathrm{~h}$, resulting in electrodes with a typical mass loading of $1.5 \mathrm{mg} / \mathrm{cm}^{2}$ to $1.8 \mathrm{mg} / \mathrm{cm}^{2}$. The electrolyte was $1 \mathrm{~mol}$ $\mathrm{NaClO}_{4}$ dissolved in a mixture of ethylene carbonate and diethyl carbonate with a volume ratio of 1:1. Glass fibers (Whatman) and pure sodium metal foil were utilized as separators and a counter electrode, respectively. An electrochemical workstation (Advanced Electrochemical System Parstat 2263) was used to test cyclic voltammograms (CVs) at a rate of $0.1 \mathrm{mV} / \mathrm{s}$ from 0.01 to $2.50 \mathrm{~V}$ ( vs. $\mathrm{Na} / \mathrm{Na}^{+}$). The galvanostatic charge-discharge measurements of $\mathrm{HC}$ and $\mathrm{F}-\mathrm{HC}$ anodes at various current densities in the potential window of $0.01 \mathrm{~V}-2.50 \mathrm{~V}$ ( $\mathrm{vs} . \mathrm{Na} / \mathrm{Na}^{+}$) were examined using a cell test instrument (Land CT2001 A, Wuhan Jinnuo Electronics Co., China). Electrochemical impedance spectroscopy (EIS) measurements were conducted with an open circuit potential at frequencies of $10^{5}-10^{-2} \mathrm{~Hz}$ with an amplitude of $5 \mathrm{mV}$. All the electrochemical tests were carried out at room temperature.

\section{Results and Discussion}

\section{Material Characterizations}

The digital photographs of pristine $\mathrm{HC}$ and F-HC (Fig. S1) reveal that the color of $\mathrm{HC}$ becomes lighter after fluorination, indicating that $\mathrm{F}$ probably bonds with $\mathrm{C}$ and thus changes the color of materials [29]. The SEM image of pristine HC (Fig. S2a) shows that the size of HC particles ranges from $4 \mu \mathrm{m}$ to $25 \mu \mathrm{m}$ with sharp edges and a rough surface composed of numerous small grains. After F doping, the FESEM images of F-HC (Fig. S2b-d) illustrate the preserved pristine morphological characteristics of $\mathrm{HC}$ without an obvious decrease in size and porous structure on the surface that differs from that of $\mathrm{HC}$ fluorinated at high temperatures [28]. This finding indicates that the conductive carbonaceous framework is still maintained without serious distortion. The corresponding FETEM images of $\mathrm{HC}$ and $\mathrm{F}-\mathrm{HC}$ (Fig. 1) illustrate that these products have a similar nanostructure consisting of randomly oriented carbon sheets. The selected area electron diffraction (SAED) pattern of HC (inset of Fig. 1a) shows scattered dots and bright rings, suggesting the existence of a partially crystalline structure, which is consistent with a previous report on $\mathrm{HC}$ [30]. However, only diffraction rings exist in the SEAD patterns of F-HC (insets of Fig. 1b-d), verifying that the ordered domains are also disrupted by $\mathrm{F}_{2}$ gas even at a relatively low temperature. The corresponding high-resolution FETEM (HRTEM) images of HC (Fig. 1e) display the disordered structure comprising some graphitic domains with a lattice distance of about $3.86 \AA$. The HRTEM images of F-HC (Fig. 1f-g) are similar to those of pristine HC, and the short-range order of carbon atoms is still observed with a remarkably enlarged lattice distance above $4.0 \AA$, which is consistent with the results of F-doped nanostructured carbon materials [23-27].

The crystal structures of $\mathrm{HC}$ and $\mathrm{F}-\mathrm{HC}$ were investigated by XRD measurements. Their XRD patterns (Fig. 2a) show that pristine HC exhibits two broad peaks at around $24^{\circ}\left((002)\right.$ crystal planes) and $42^{\circ}((100)$ crystal planes), which confirm the polycrystalline nature [31]. During mild fluorination, the ordered structures in $\mathrm{HC}$ are destroyed by $\mathrm{F}_{2}$, as indicated by the decreased intensities of diffraction peaks. Therefore, the diffraction peaks of $\mathrm{F}-\mathrm{HC}$ broaden, and the (002) plane reflections shift to lower angles, illustrating the increased interlayer distance, which is consistent with the HRTEM results. The expanded interlayer distance of $\mathrm{F}-\mathrm{HC}$ is attributed to the formation of $\mathrm{C}-\mathrm{F}$ bonds perpendicular to the planar graphene lattice and the repulsion between $\mathrm{F}$ atoms with the highest electronegativity, which is favorable to promoting $\mathrm{Na}^{+}$intercalation in graphitic layers. Nevertheless, the interlayer distance of $\mathrm{F}-\mathrm{HC} 150$ is slightly smaller than that of $\mathrm{F}-\mathrm{HC} 100$ probably because more covalent $\mathrm{C}-\mathrm{F}$ bonds form than semi-ionic $\mathrm{C}-\mathrm{F}$ bonds at high fluorination temperatures combined with HRTEM
Fig. 1 TEM images of a HC, b F-HC50, c F-HC100, d F$\mathrm{HC} 150$, and HRTEM images of e $\mathrm{HC}, \mathbf{f} \mathrm{F}-\mathrm{HC} 50, \mathbf{g}$ F-HC100, h F-HC150. Insets are the corresponding SAED patterns of $\mathrm{HC}$ and $\mathrm{F}-\mathrm{HC}$
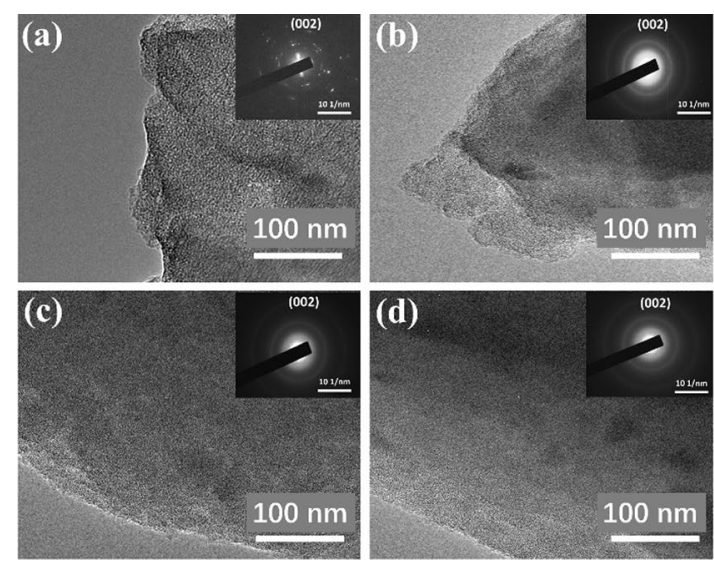

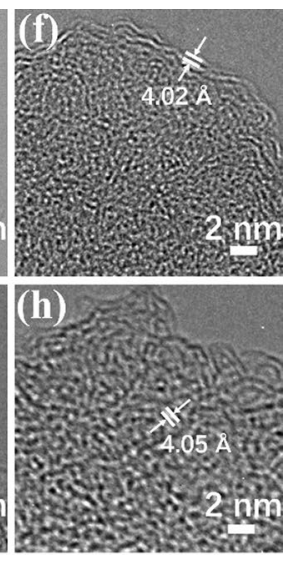


Fig. 2 a XRD patterns, b Raman spectra, c $\mathrm{N}_{2}$ isotherms, and $\mathbf{d}$ pore size distribution of $\mathrm{HC}$ and $\mathrm{F}-\mathrm{HC}$
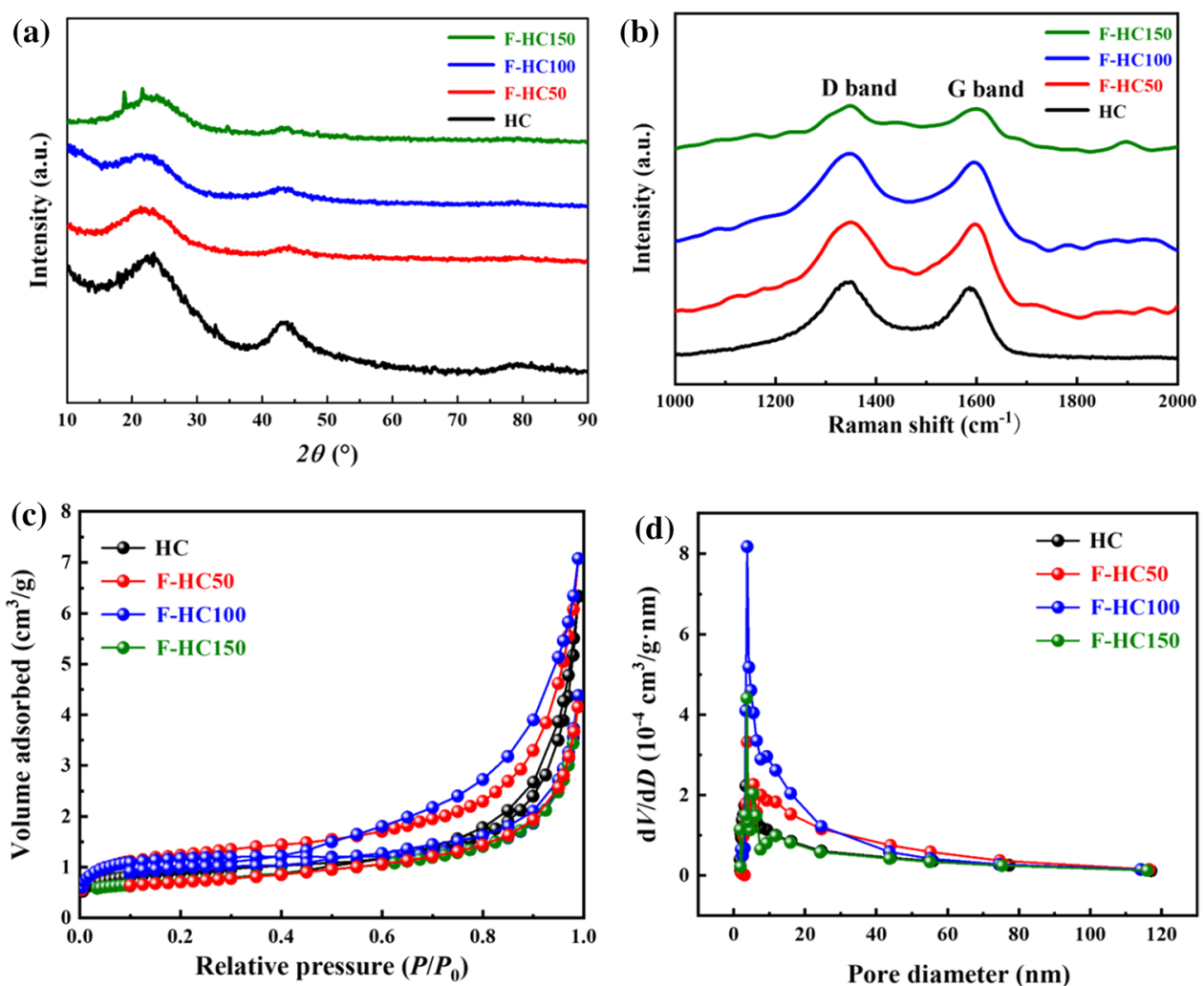

and XRD results; furthermore, the former bond length is slightly shorter than that of the latter [32]. Raman spectroscopy was conducted to detect the structural change after $\mathrm{F}$ doping. The Raman spectra of $\mathrm{HC}$ and F-HC (Fig. 2b) present two broad peaks at $1350 \mathrm{~cm}^{-1}$ and $1580 \mathrm{~cm}^{-1}$, which correspond to the D-band (defect-induced mode) and the G-band (crystalline graphite band), respectively. The G-band of $\mathrm{HC}$ appears at $1594 \mathrm{~cm}^{-1}$, but the G-bands of the F-HC samples form at $1600 \mathrm{~cm}^{-1}$. The upshift of the $\mathrm{G}$-band is ascribed to the formation of $\mathrm{C}-\mathrm{F}$ bonds [33]. The intensity ratios of D- and G-bands $\left(I_{\mathrm{D}} / I_{\mathrm{G}}\right)$ of $\mathrm{HC}, \mathrm{F}-\mathrm{HC} 50, \mathrm{~F}-\mathrm{HC} 100$, and $\mathrm{F}-\mathrm{HC} 150$ are $1.01,1.02,1.04$, and 1.07, respectively. The gradually increased $I_{\mathrm{D}} / I_{\mathrm{G}}$ indicates that $\mathrm{F}$ destroys $\mathrm{sp}^{2}$ graphitic domains, suggesting $I_{\mathrm{D}} / I_{\mathrm{G}}$ is highly dependent on the $\mathrm{F}$ doping degree.

The surficial characterizations of $\mathrm{HC}$ and $\mathrm{F}-\mathrm{HC}$ were examined by $\mathrm{N}_{2}$ adsorption-desorption isotherm measurements at $77 \mathrm{~K}$. The surface areas and total pore volumes of $\mathrm{HC}$ and $\mathrm{F}-\mathrm{HC}$ are listed in Table S1. The low BET specific surface area of $\mathrm{HC}$ and $\mathrm{F}-\mathrm{HC}$ implies the absence of micropores. This result can be further demonstrated by their $\mathrm{N}_{2}$ isotherms (Fig. 2c), which are classified as type III curves, indicating that abundant mesopores and macropores exist in HC and F-HC. The slightly increased surface area after $\mathrm{F}$ doping is assigned to the etching of graphitic frameworks by highly active $\mathrm{F}_{2}$, resulting in the formation of some defects and a subsequent increase in the surface area [34].
The corresponding pore size distributions were acquired via nonlocal density functional theory calculations. The similar features of the pore size distribution of $\mathrm{HC}$ and $\mathrm{F}-\mathrm{HC}$ (Fig. 2d) indicate the maintained morphological structure of HC after F doping, unlike fluorination at high temperatures. The pores of all samples are mainly distributed in a mesoporous range, approximately from 2 to $20 \mathrm{~nm}$; however, the peak maxima of the pore size distribution of $\mathrm{F}-\mathrm{HC}$ is higher than that of HC. This difference can also be explained by the formed defects after $\mathrm{F}$ doping.

The XPS extensive survey spectra of the F-HC samples (Fig. S3) exhibit the robust F signals around $686.5 \mathrm{eV}$, confirming that $\mathrm{HC}$ is successfully doped with $\mathrm{F}$ [35]. F doping can also be demonstrated by the element mapping images of F-HC (Fig. S4) because of the high activity of $\mathrm{F}_{2}$ gas, even at low temperatures. The F-doping content of F-HC increases with fluorination temperature because of the improved kinetics to react with $\mathrm{C}$ atoms. The molar ratios of $\mathrm{F}$ in $\mathrm{F}-\mathrm{HC} 50, \mathrm{~F}-\mathrm{HC} 100$, and $\mathrm{F}-\mathrm{HC} 150$ are 8.54 at.\%, 18.46 at. $\%$, and 23.18 at.\%, respectively. A high-resolution XPS survey was subsequently conducted to further investigate the type of $\mathrm{F}$ doping species. The high-resolution $\mathrm{C} 1 \mathrm{~s}$ spectra of $\mathrm{F}-\mathrm{HC}$ (Fig. 3a-c) are deconvoluted to fit the existing chemical species; the peaks centered at $284.8 \mathrm{eV}$, $285.4 \mathrm{eV}, 285.9 \mathrm{eV}, 286.7 \mathrm{eV}$, and $289.2 \mathrm{eV}$ in the $\mathrm{C} 1 \mathrm{~s}$ spectra can be assigned to the $\mathrm{sp}^{2}$-hybridized $\mathrm{C}, \mathrm{sp}^{3}$-hybridized $\mathrm{C}, \mathrm{C}-\mathrm{O}$, semi-ionic $\mathrm{C}-\mathrm{F}$ bonds, and covalent $\mathrm{C}-\mathrm{F}$ bond, 

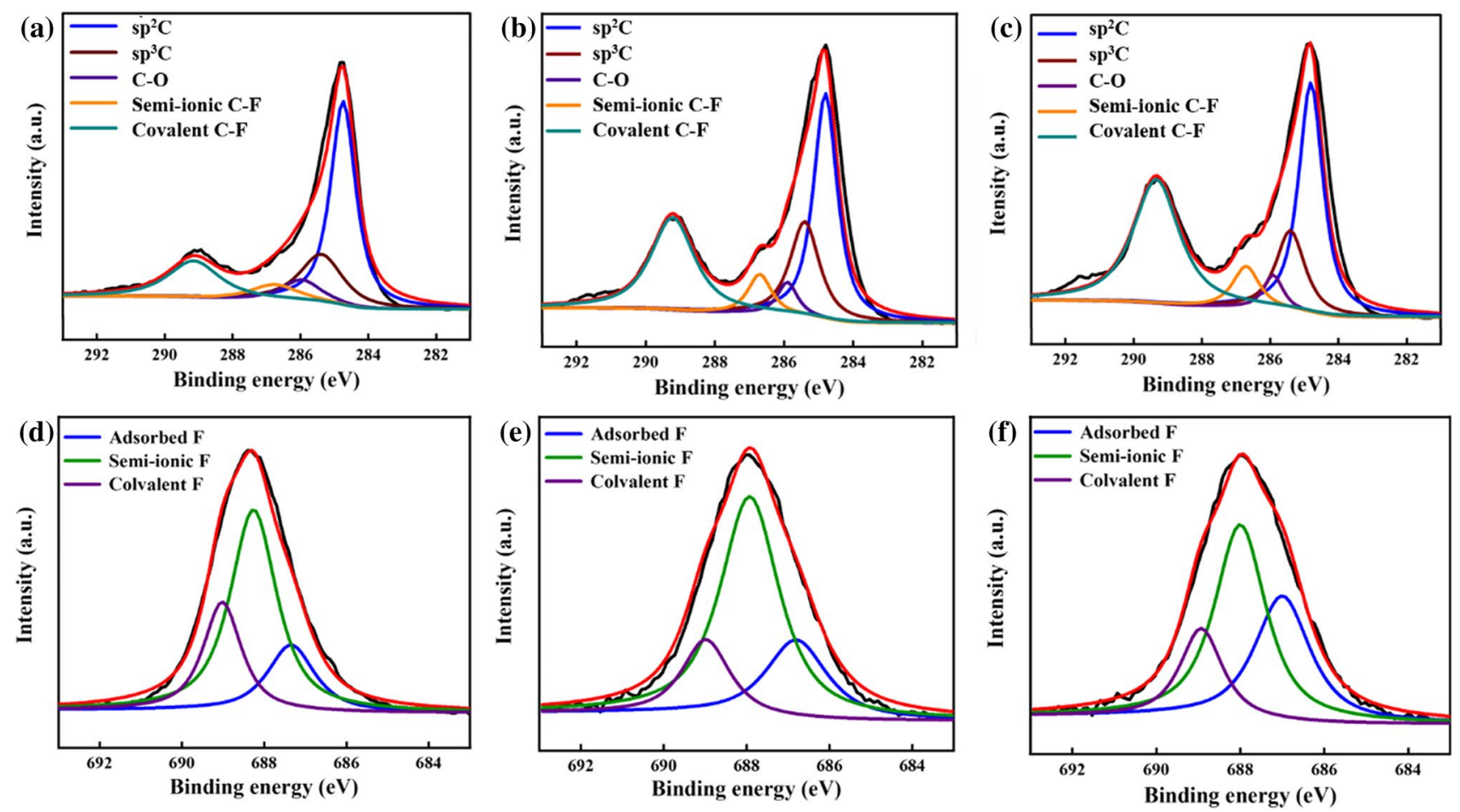

Fig. 3 XPS C1s spectra of a F-HC50, b F-HC100, c F-HC150, and XPS F1s spectra of d F-HC50, e F-HC100, f F-HC150

respectively [36]. As temperature increases, the intensity of the peak assigned to the covalent $\mathrm{C}-\mathrm{F}$ bond enhances greatly, but the amount of semi-ionic $\mathrm{C}-\mathrm{F}$ bond is reduced slightly because of the formation of fluorographene domains rather than the scattered $\mathrm{F}$ atoms on the graphitic framework [37]. The high-resolution F1s spectra of F-HC (Fig. 3d-f) exhibit three peaks at $686.5 \mathrm{eV}, 687.4 \mathrm{eV}$, and $688.6 \mathrm{eV}$, which are ascribed to different types of fluorinated species, namely physically adsorbed and trapped F, semi-ionically bonded F, and covalently bonded F, respectively [38]. The intensity of the peak assigned to the adsorbed $\mathrm{F}$ decreases as temperature increases because of the high $\mathrm{F}_{2}$ activity at high temperatures. The existence of a semi-ionic $\mathrm{C}-\mathrm{F}$ bond in all the prepared F-HC samples helps enhance the electrical conductivity of electrodes [39]. The amount of covalently bonded $\mathrm{F}$ in $\mathrm{F}-\mathrm{HC}$ gradually increases with fluorination temperature, and this finding agrees with the result of the $\mathrm{C} 1 \mathrm{~s}$ spectra. The detailed fluorinated species and their contents are listed in Table S2.

\section{Electrochemical Measurements}

The electrochemical performance of the $\mathrm{HC}$ and $\mathrm{F}-\mathrm{HC}$ samples as SIB anodes was evaluated. CV measurements were performed at a rate of $0.1 \mathrm{mV} / \mathrm{s}$ in the range of $0.01 \mathrm{~V}-2.50 \mathrm{~V}$ (vs. $\mathrm{Na}^{+} / \mathrm{Na}$ ) to investigate the mechanism of the electrochemical reaction. The first corresponding three cycles are presented in Fig. 4a-d. Previous studies on HC $[40,41]$ showed that all the CV curves consist of one pair of sharp reduction and oxidation peaks between $0.01 \mathrm{~V}$ and $0.25 \mathrm{~V}$, corresponding to $\mathrm{Na}^{+}$insertion and extraction in graphitic layers. In comparison with the CV curve of pristine $\mathrm{HC}$, notable reduction peaks exist between $0.25 \mathrm{~V}$ and $1.00 \mathrm{~V}$ in the first cycle of the CV curves of F-HC. These peaks are ascribed to the formation of a solid electrolyte interface (SEI) because of the generated defects after F doping and irreversible reactions with F. This finding can be demonstrated by the disappearance of these peaks in the subsequent cycles shown in the $\mathrm{CV}$ curves of $\mathrm{F}-\mathrm{HC}$. The $\mathrm{CV}$ curves in the second and third cycles of $\mathrm{HC}$ and $\mathrm{F}-\mathrm{HC}$ overlap, indicating the stable electrochemical reactions of these anode materials.

A galvanostatic discharge/charge test was conducted to investigate the electrochemical performance of $\mathrm{HC}$ and F-HC as SIB anodes. The discharge-charge profiles of HC and $\mathrm{F}-\mathrm{HC}$ at the current density of $50 \mathrm{~mA} / \mathrm{g}$ in the first three cycles are shown in Fig. 4e-f. The presence of the sloping region at a high potential and the plateau region at a low potential represents the typical $\mathrm{Na}^{+}$storage behavior in $\mathrm{HC}$ [42]. The sloping region above $0.1 \mathrm{~V}$ corresponds to the $\mathrm{Na}^{+}$storage into defects and edge sites, whereas the plateau region below $0.1 \mathrm{~V}$ is ascribed to $\mathrm{Na}^{+}$stored in the interlayer spacing [43]. Pristine $\mathrm{HC}$ electrode delivers the initial discharge capacity of $350 \mathrm{mAh} / \mathrm{g}$, with the first charge 
(a)

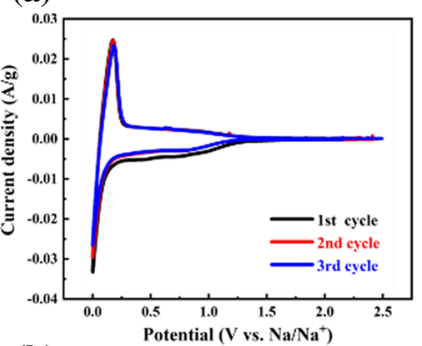

(b)

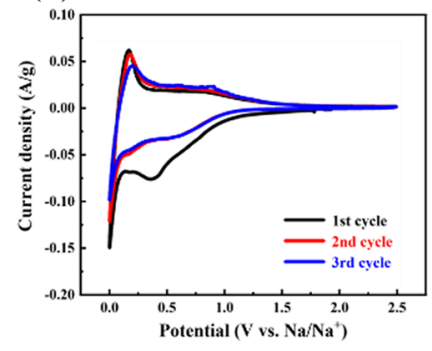

(c)

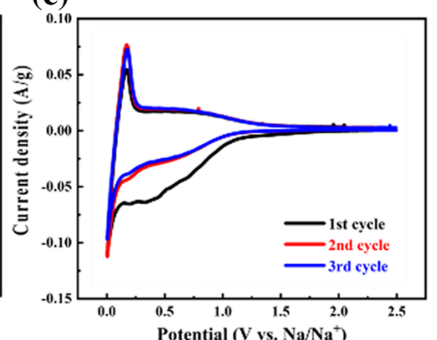

(d)

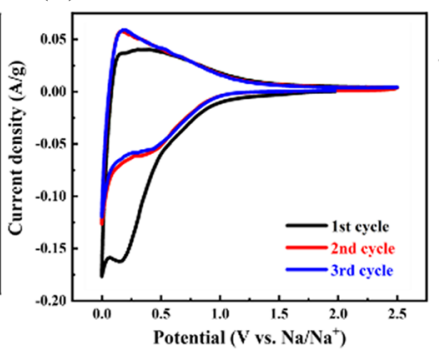

(e)

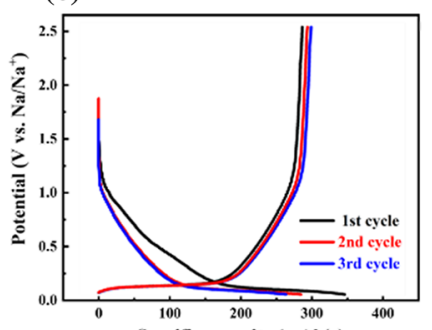

(f)

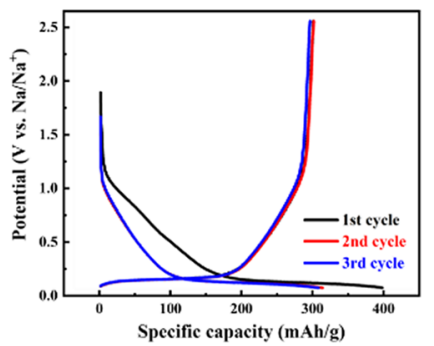

(g)

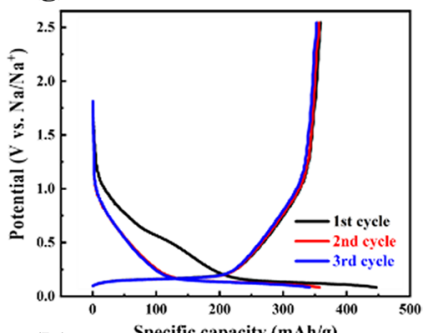

(h)

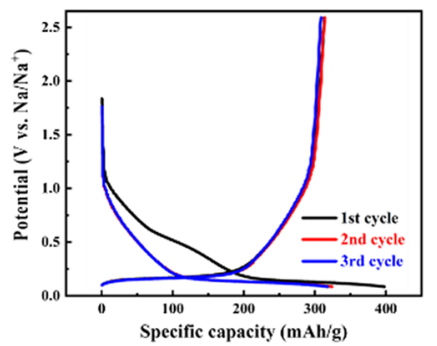

Fig. $4 \mathrm{CV}$ curves of a $\mathrm{HC}$, b F-HC50, $\mathbf{c}$ F-HC100, and $\mathbf{d}$ F-HC150 at the scan rate of $0.1 \mathrm{mV} / \mathrm{s}$. Galvanostatic discharge/charge profiles of e $\mathrm{HC}$, f F-HC50, g F-HC100, and h F-HC150 at the current density of $50 \mathrm{~mA} / \mathrm{g}$ in the potential range of $0.01 \mathrm{~V}-2.50 \mathrm{~V}\left(\mathrm{vs} . \mathrm{Na} / \mathrm{Na}{ }^{+}\right.$)

capacity of $289 \mathrm{mAh} / \mathrm{g}$; the corresponding Coulombic efficiency is $82.57 \%$, which is caused by SEI formation and electrolyte decomposition [40]. The initial discharge capacities of $\mathrm{F}-\mathrm{HC} 50, \mathrm{~F}-\mathrm{HC} 100$, and $\mathrm{F}-\mathrm{HC} 150$ are $401 \mathrm{mAh} / \mathrm{g}$, $448 \mathrm{mAh} / \mathrm{g}$, and $398 \mathrm{mAh} / \mathrm{g}$, respectively, and the subsequent charge capacities are $323 \mathrm{mAh} / \mathrm{g}, 358 \mathrm{mAh} / \mathrm{g}$, and $317 \mathrm{mAh} / \mathrm{g}$, corresponding to the Coulombic efficiencies of $80.54 \%, 78.13 \%$, and $79.65 \%$, respectively. The reduced Coulombic efficiency of $\mathrm{F}-\mathrm{HC}$ compared with that of $\mathrm{HC}$ is caused by the created defects and formed C-F bonds. This observation is also reflected in their CV curves. In the following cycles, the discharge and charge profiles of $\mathrm{HC}$ and F-HC overlap with each other, and the reversible specific capacities stabilize. As fluorination temperature increases, the specific capacities in the sloping region of the $\mathrm{F}-\mathrm{HC}$ samples are slightly higher than those of pristine HC, confirming the existence of defects on the graphitic framework after the mild fluorination treatment with HC [44]. The plateau capacities of the $\mathrm{F}-\mathrm{HC}$ samples also increase compared with those of pristine $\mathrm{HC}$, and this increase is caused by the interlayer distance enlargement after F doping; a similar behavior has also been observed in S- or P-doped HC [20]. The enhanced specific capacity of F-HC further demonstrates that $\mathrm{F}$ doping is effective in promoting $\mathrm{Na}^{+}$storage in $\mathrm{HC}$ because of defective active sites and the expansion of the interlayer distance after $\mathrm{F}$ doping. However, the specific capacity of $\mathrm{F}-\mathrm{HC} 150$ is slightly less than that of $\mathrm{F}-\mathrm{HC} 100$, which is caused by the decreased interlayer distance due to the formation of the covalent $\mathrm{C}-\mathrm{F}$ bond at high temperatures. This observation corresponds to the XRD pattern and XPS spectra.

The cycling performance of $\mathrm{HC}$ and $\mathrm{F}-\mathrm{HC}$ at a current density of $50 \mathrm{~mA} / \mathrm{g}$ is shown in Fig. $5 \mathrm{a}$. These anode materials exhibit outstanding cycling stability because of
Fig. 5 a Cycling performance at $50 \mathrm{~mA} / \mathrm{g}$ in the potential range of $0.01 \mathrm{~V}-2.50 \mathrm{~V}$ (vs. Na/ $\mathrm{Na}^{+}$) and $\mathbf{b}$ rate performance at $50 \mathrm{~mA} / \mathrm{g}, 100 \mathrm{~mA} / \mathrm{g}, 200 \mathrm{~mA} / \mathrm{g}$, and $500 \mathrm{~mA} / \mathrm{g}$ of $\mathrm{HC}$ and $\mathrm{F}-\mathrm{HC}$ (a)

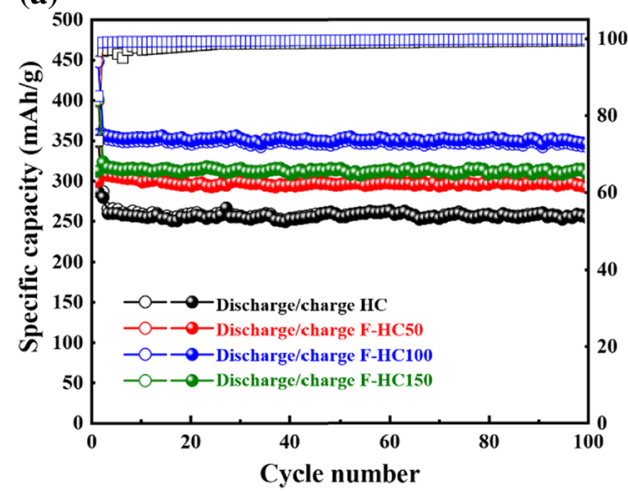

(b)

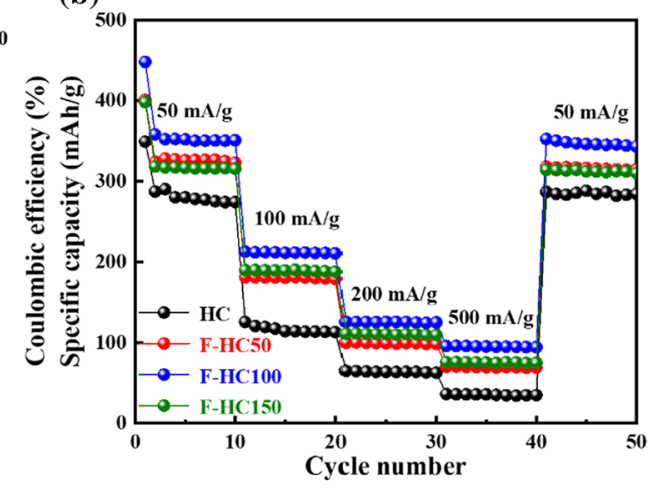


Fig. 6 TEM images of a $\mathrm{HC}$, b F-HC50, c F-HC100, d FHC150 and HRTEM images of e $\mathrm{HC}, \mathbf{f} \mathrm{F}-\mathrm{HC} 50, \mathbf{g} \mathrm{F}-\mathrm{HC} 100$, h $\mathrm{F}-\mathrm{HC} 150$ after 100 cycles at $50 \mathrm{~mA} / \mathrm{g}$. Insets are the corresponding SAED patterns of $\mathrm{HC}$ and $\mathrm{F}-\mathrm{HC}$ after the cycling test
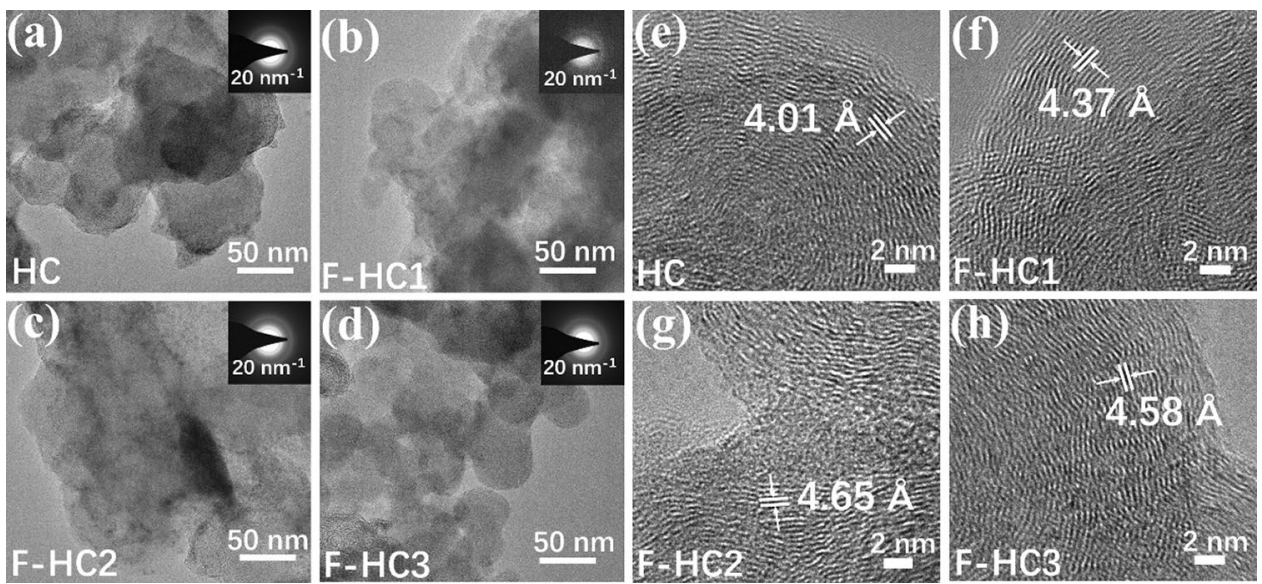

the formed crystalline structure of HC without the restacking and aggregation of graphitic layers during sodiation and desodiation. The discharge capacities of HC, F-HC50, $\mathrm{F}-\mathrm{HC} 100$, and $\mathrm{F}-\mathrm{HC} 150$ are $266 \mathrm{mAh} / \mathrm{g}, 304 \mathrm{mAh} / \mathrm{g}$, $343 \mathrm{mAh} / \mathrm{g}$, and $313 \mathrm{mAh} / \mathrm{g}$ after 100 cycles, corresponding to the capacity retentions of $92.04 \%, 94.12 \%, 95.81 \%$, and $98.74 \%$, respectively. The rate capabilities of $\mathrm{HC}$ and F-HC were estimated by measuring the specific capacities at various current densities (Fig. 5b). As the current density increases, the capacities of $\mathrm{HC}$ and $\mathrm{F}-\mathrm{HC}$ reduce gradually because of the aggravated polarization at a high current density. Furthermore, the rate capability of the prepared $\mathrm{F}-\mathrm{HC}$ samples is better than that of pristine $\mathrm{HC}$ because of the larger interlayer distance caused by $\mathrm{F}$ and semi-ionic $\mathrm{C}-\mathrm{F}$ bond; this characteristic then facilitates the transfer of $\mathrm{Na}^{+}$ and electrons throughout the electrode [23]. Among these electrodes, F-HC100 exhibits the best rate capability, which delivers the initial specific capacities of $353 \mathrm{mAh} / \mathrm{g}, 213$ $\mathrm{mAh} / \mathrm{g}, 126 \mathrm{mAh} / \mathrm{g}$, and $96 \mathrm{mAh} / \mathrm{g}$ at current densities of $50 \mathrm{~mA} / \mathrm{g}, 100 \mathrm{~mA} / \mathrm{g}, 200 \mathrm{~mA} / \mathrm{g}$, and $500 \mathrm{~mA} / \mathrm{g}$, respectively. The typical discharge and charge profiles of F-HC100 at different current densities are illustrated in Fig. S5. The specific capacity mainly decreases in the low-plateau region rather than the sloping region, possibly because of the slower kinetics of the intercalation of $\mathrm{Na}^{+}$into graphitic layers than the adsorption of $\mathrm{Na}^{+}$in pores [45]. When the current density is back to $50 \mathrm{~mA} / \mathrm{g}, \mathrm{HC}$ and $\mathrm{F}-\mathrm{HC}$ can recover almost all of their capacities after about ten cycles, which verifies the excellent cycling stability of these anode materials even at high current densities. Therefore, the rate capability of $\mathrm{F}-\mathrm{HC}$ as a SIB anode further improves through the optimization of electrolyte components. The energy density of $\mathrm{F}-\mathrm{HC}$ products in this study was compared with that in previously reported SIB cathodes (Table S3).

EIS was conducted to investigate the different kinetic parameters of $\mathrm{HC}$ and $\mathrm{F}-\mathrm{HC}$ anodes. The impedance parameters of the Nyquist plots of $\mathrm{HC}$ and F-HC after 100 cycles at the current density of $50 \mathrm{~mA} / \mathrm{g}$ (Fig. S6) were fitted according to the equivalent circuit (inset of Fig. S6). The semicircle occurring in the medium-to-high frequency region represents the charge transfer resistance $\left(R_{\mathrm{ct}}\right)$, and F-HC100 exhibits the smallest $R_{\mathrm{ct}}$ among the anode materials, which are attributed to the enlarged interlayer distance and electrically conductive C-F bond [46]. The linear tail in the low-frequency region is ascribed to the Warburg impedance $\left(Z_{\mathrm{w}}\right)$, which is associated with $\mathrm{Na}^{+}$diffusion in anodes [47]. The close straight slope in the low-frequency region of $\mathrm{HC}$ and $\mathrm{F}-\mathrm{HC}$ represents the similar $\mathrm{Na}^{+}$diffusion coefficient because of the same morphology and surface area.

The morphological change in these anode materials during sodiation/desodiation was explored to demonstrate the structural stability of $\mathrm{F}-\mathrm{HC}$ as the SIB anode. After 100 cycles at $50 \mathrm{~mA} / \mathrm{g}$, the SEM images of $\mathrm{HC}$ and F-HC (Fig. S7) demonstrate that the original morphological characteristics of $\mathrm{HC}$ and $\mathrm{F}-\mathrm{HC}$ are maintained, confirming the excellent cycling stability of these anode materials. The rough layer on $\mathrm{HC}$ and $\mathrm{F}-\mathrm{HC}$ particles is considered as the SEI film formed by electrolyte decomposition during sodiation [48]. This film covers the original smooth surface of these anode materials. The TEM images of $\mathrm{HC}$ and $\mathrm{F}-\mathrm{HC}$ after 100 cycles at $50 \mathrm{~mA} / \mathrm{g}$ (Fig. 6a-d) further illustrate the retained granular morphology of these anode materials with a roughened surface. However, the corresponding SAED patterns of $\mathrm{HC}$ and $\mathrm{F}-\mathrm{HC}$ transform from the scattered dots and bright rings to ambiguous and diffuse electron diffractions; this result indicates that the crystalline graphitic domains in these anode materials are disrupted during $\mathrm{Na}^{+}$ insertion/extraction [49]. The HRTEM images of HC and F-HC (Fig. 6e-f) show that the interlayer distance expands compared with those of their original values (Fig. 2e-f). The intercalation of $\mathrm{Na}^{+}$into the graphitic domains of $\mathrm{HC}$ and $\mathrm{F}-\mathrm{HC}$ further increases the interlayer distance. F-HC100 shows an interlayer distance of $4.65 \AA$, further verifying the enhanced $\mathrm{Na}^{+}$storage capacity after $\mathrm{F}$ doping. In addition, the obviously reserved stacked graphitic layers demonstrate the excellent cycling stabilities of $\mathrm{HC}$ after F doping [50]. 
These results demonstrate the effective improvement of $\mathrm{F}$ doping to improve the electrochemical performance of $\mathrm{HC}$ as a SIB anode [51]. Furthermore, $\mathrm{F}$ doping is achieved through mild fluorination at relatively low temperatures. Therefore, this process is feasible and practical for scalable production with controllable modification [52-55].

\section{Conclusion}

In summary, $\mathrm{F}-\mathrm{HC}$ synthesis through mild fluorination not only improved the fluorine doping content but also preserved the carbon skeleton configuration of a carbon material precursor. The contents of doped $\mathrm{F}$ and fluorinated species were adjusted in terms of fluorination temperature. F-HC obtained at different temperatures was used as a SIB anode material, and the specific capacity, cycling stability, and rate capability were improved compared with those of pristine HC. These improvements were caused by the expanded interlayer distance and abundant semi-ionic $\mathrm{C}-\mathrm{F}$ bond, which facilitated the intercalation of $\mathrm{Na}^{+}$into graphitic layers and guaranteed the electrical conductivity of electrodes. F-HC100 delivered the highest reversible capacity of 358 $\mathrm{mAh} / \mathrm{g}$ at $50 \mathrm{~mA} / \mathrm{g}$, with an initial Coulombic efficiency of $78.13 \%$. It also retained the capacity of $343 \mathrm{mAh} / \mathrm{g}$ after 100 cycles at $50 \mathrm{~mA} / \mathrm{g}$. Furthermore, the almost recovered capacity after the rate capability test at a high current density demonstrated satisfactory cycling stability even at a high current density. The study provided a convenient, efficient, and controllable strategy to modify the electrochemical performance of $\mathrm{HC}$ as a SIB anode with a high capacity in the low-voltage region. Therefore, F-HC could be used as a favorable high-energy density SIB anode.

Supplementary Information The online version contains supplementary material available at https://doi.org/10.1007/s12209-021-00311-w.

Acknowledgements This work was financially supported by the State Grid Headquarters Science and Technology Project (No. 5455DW190009).

\section{Declarations}

Conflict of interest The authors declare that there is no conflict of interests.

Open Access This article is licensed under a Creative Commons Attribution 4.0 International License, which permits use, sharing, adaptation, distribution and reproduction in any medium or format, as long as you give appropriate credit to the original author(s) and the source, provide a link to the Creative Commons licence, and indicate if changes were made. The images or other third party material in this article are included in the article's Creative Commons licence, unless indicated otherwise in a credit line to the material. If material is not included in the article's Creative Commons licence and your intended use is not permitted by statutory regulation or exceeds the permitted use, you will need to obtain permission directly from the copyright holder. To view a copy of this licence, visit http://creativecommons.org/licenses/by/4.0/.

\section{References}

1. Larcher D, Tarascon JM (2015) Towards greener and more sustainable batteries for electrical energy storage. Nat Chem 7(1):19-29

2. Palomares V, Serras P, Villaluenga I et al (2012) Na-ion batteries, recent advances and present challenges to become low cost energy storage systems. Energy Environ Sci 5(3):5884

3. Pan HL, Hu YS, Chen LQ (2013) Room-temperature stationary sodium-ion batteries for large-scale electric energy storage. Energy Environ Sci 6(8):2338

4. Goodenough JB, Park KS (2013) The Li-ion rechargeable battery: a perspective. J Am Chem Soc 135(4):1167-1176

5. Kim SW, Seo DH, Ma XH et al (2012) Electrode materials for rechargeable sodium-ion batteries: potential alternatives to current lithium-ion batteries. Adv Energy Mater 2(7):710-721

6. Slater MD, Kim D, Lee E et al (2013) Sodium-ion batteries. Adv Funct Mater 23(8):947-958

7. Liu YY, Merinov BV, Goddard WA III (2016) Origin of low sodium capacity in graphite and generally weak substrate binding of $\mathrm{Na}$ and $\mathrm{Mg}$ among alkali and alkaline earth metals. PNAS 113(14):3735-3739

8. Moriwake H, Kuwabara A, Fisher CAJ et al (2017) Why is sodiumintercalated graphite unstable? RSC Adv 7(58):36550-36554

9. Li L, Zheng Y, Zhang SL et al (2018) Recent progress on sodium ion batteries: potential high-performance anodes. Energy Environ Sci 11(9):2310-2340

10. Sun Y, Guo SH, Zhou HS (2019) Exploration of advanced electrode materials for rechargeable sodium-ion batteries. Adv Energy Mater 9(23): 1800212

11. Perveen T, Siddiq M, Shahzad N et al (2020) Prospects in anode materials for sodium ion batteries - a review. Renew Sustain Energy Rev 119:109549

12. Hou HS, Qiu XQ, Wei WF et al (2017) Carbon anode materials for advanced sodium-ion batteries. Adv Energy Mater 7(24):1602898

13. Thomas P, Billaud D (2002) Electrochemical insertion of sodium into hard carbons. Electrochim Acta 47(20):3303-3307

14. Xiao B, Rojo T, Li X (2019) Hard carbon as sodium-ion battery anodes: progress and challenges. Chemsuschem 12(1):133-144

15. Bai PX, He YW, Zou XX et al (2018) Elucidation of the sodium-storage mechanism in hard carbons. Adv Energy Mater 8(15):1703217

16. Qiu S, Xiao LF, Sushko ML et al (2017) Manipulating adsorptioninsertion mechanisms in nanostructured carbon materials for highefficiency sodium ion storage. Adv Energy Mater 7(17):1700403

17. Alvin S, Yoon D, Chandra C et al (2019) Revealing sodium ion storage mechanism in hard carbon. Carbon 145:67-81

18. Xiao LF, Cao YL, Xiao J et al (2012) High capacity, reversible alloying reactions in $\mathrm{SnSb} / \mathrm{C}$ nanocomposites for Na-ion battery applications. Chem Commun 48(27):3321

19. Zhang YF, Pan AQ, Ding L et al (2017) Nitrogen-doped yolkshell-structured CoSe/C dodecahedra for high-performance sodium ion batteries. ACS Appl Mater Interfaces 9(4):3624-3633

20. Li ZF, Bommier C, Chong ZS et al (2017) Mechanism of Na-ion storage in hard carbon anodes revealed by heteroatom doping. Adv Energy Mater 7(18): 1602894

21. Chen SL, Feng F, Ma ZF (2020) Lignin-derived nitrogen-doped porous ultrathin layered carbon as a high-rate anode material for sodium-ion batteries. Compos Commun 22:100447

22. An HR, Li Y, Feng YY et al (2018) Reduced graphene oxide doped predominantly with $\mathrm{CF} 2$ groups as a superior anode material for long-life lithium-ion batteries. Chem Commun 54(22):2727-2730 
23. Wang PZ, Qiao B, Du YC et al (2015) Fluorine-doped carbon particles derived from Lotus petioles as high-performance anode materials for sodium-ion batteries. J Phys Chem C 119(37):21336-21344

24. Hong SM, Etacheri V, Hong CN et al (2017) Enhanced lithiumand sodium-ion storage in an interconnected carbon network comprising electronegative fluorine. ACS Appl Mater Interfaces 9(22):18790-18798

25. He QC, Jiang JH, Zhu JL et al (2020) A facile and cost effective synthesis of nitrogen and fluorine Co-doped porous carbon for high performance Sodium ion battery anode material. J Power Sources 448:227568

26. An HR, Li Y, Gao Y et al (2017) Free-standing fluorine and nitrogen co-doped graphene paper as a high-performance electrode for flexible sodium-ion batteries. Carbon 116:338-346

27. Yan XM, Liang ST, Shi HT et al (2021) Nitrogen-enriched carbon nanofibers with tunable semi-ionic $\mathrm{CF}$ bonds as a stable long cycle anode for sodium-ion batteries. J Colloid Interface Sci 583:535-543

28. Zhou RX, Li Y, Feng YY et al (2020) The electrochemical performances of fluorinated hard carbon as the cathode of lithium primary batteries. Compos Commun 21:100396

29. Stevens DA, Dahn JR (2000) High capacity anode materials for rechargeable sodium-ion batteries. J Electrochem Soc 147(4):1271

30. Xu DF, Chen CJ, Xie J et al (2016) A hierarchical N/S-codoped carbon anode fabricated facilely from cellulose/polyaniline microspheres for high-performance sodium-ion batteries. Adv Energy Mater 6(6):1501929

31. Li JF, Han L, Zhang DF et al (2019) N, S co-doped porous carbon microtubes with high charge/discharge rates for sodium-ion batteries. Inorg Chem Front 6(8):2104-2111

32. Sato Y, Itoh K, Hagiwara R et al (2004) On the so-called "semi-ionic" C-F bond character in fluorine-GIC. Carbon 42(15):3243-3249

33. Nair RR, Ren WC, Jalil R et al (2010) Fluorographene: a two-dimensional counterpart of teflon. Small 6(24):2877-2884

34. Park S, Lee KS, Bozoklu G et al (2008) Graphene oxide papers modified by divalent ions-enhancing mechanical properties via chemical cross-linking. ACS Nano 2(3):572-578

35. Lee JM, Kim SJ, Kim JW et al (2009) A high resolution XPS study of sidewall functionalized MWCNTs by fluorination. J Ind Eng Chem 15(1):66-71

36. Wang WZ, Li Y, Feng YY et al (2018) Asymmetric self-supporting hybrid fluorinated carbon nanotubes/carbon nanotubes sponge electrode for high-performance lithium-polysulfide battery. Chem Eng J 349:756-765

37. Chen YL, Li Y, Yao FN et al (2019) Nitrogen and fluorine codoped holey graphene hydrogel as a binder-free electrode material for flexible solid-state supercapacitors. Sustain Energy Fuels 3(9):2237-2245

38. Li Y, Feng YY, Feng W (2013) Deeply fluorinated multi-wall carbon nanotubes for high energy and power densities lithium/carbon fluorides battery. Electrochim Acta 107:343-349

39. An HR, Li Y, Long P et al (2016) Hydrothermal preparation of fluorinated graphene hydrogel for high-performance supercapacitors. J Power Sources 312:146-155

40. Lotfabad EM, Ding J, Cui K et al (2014) High-density sodium and lithium ion battery anodes from banana peels. ACS Nano 8(7):7115-7129

41. Stevens DA, Dahn JR (2001) The mechanisms of lithium and sodium insertion in carbon materials. J Electrochem Soc 148(8):A803

42. Gotoh K, Ishikawa T, Shimadzu S et al (2013) NMR study for electrochemically inserted $\mathrm{Na}$ in hard carbon electrode of sodium ion battery. J Power Sources 225:137-140

43. Simone V, Boulineau A, de Geyer A et al (2016) Hard carbon derived from cellulose as anode for sodium ion batteries: dependence of electrochemical properties on structure. J Energy Chem 25(5):761-768
44. Song HW, Li N, Cui H et al (2014) Enhanced storage capability and kinetic processes by pores- and hetero-atoms- riched carbon nanobubbles for lithium-ion and sodium-ion batteries anodes. Nano Energy 4:81-87

45. Alvin S, Cahyadi HS, Hwang J et al (2020) Intercalation mechanisms: revealing the intercalation mechanisms of lithium, sodium, and potassium in hard carbon (adv. energy mater. 20/2020). Adv Energy Mater 10(20):2070093

46. Mukherjee R, Thomas AV, Krishnamurthy A et al (2012) Photothermally reduced graphene as high-power anodes for lithium-ion batteries. ACS Nano 6(9):7867-7878

47. Li HM, Wu TT, Chen YY et al (2021) Self-crosslinked herringbone dihydrophenazine derivatives for high performance organic batteries. Compos Commun 28:100947

48. Pol VG, Lee E, Zhou DH et al (2014) Spherical carbon as a new high-rate anode for sodium-ion batteries. Electrochim Acta 127:61-67

49. Shen YL, Sun SJ, Yang M et al (2019) Typha-derived hard carbon for high-performance sodium ion storage. J Alloy Compd 784:1290-1296

50. Li ZF, Ma L, Surta TW et al (2016) High capacity of hard carbon anode in Na-ion batteries unlocked by POx doping. ACS Energy Lett 1(2):395-401

51. Liao WM, Shan ZQ, Tian JH et al (2020) Facile Fabrication of $\mathrm{Fe}_{3} \mathrm{O}_{4} @ \mathrm{TiO}_{2} @ \mathrm{C}$ Yolk-Shell Spheres as Anode Material for Lithium Ion Batteries. Trans Tianjin Univ 26(1):3-12

52. Cao ZJ, Liu HT, Huang WL et al (2020) Hydrogen bonding-assisted synthesis of silica/oxidized mesocarbon microbeads encapsulated in amorphous carbon as stable anode for optimized/enhanced lithium storage. Trans Tianjin Univ 26(1):13-21

53. Yan Y, Ma ZY, Lin HJ et al (2019) Hydrogel self-templated synthesis of $\mathrm{Na}_{3} \mathrm{~V}_{2}\left(\mathrm{PO}_{4}\right)_{3} @ \mathrm{C} @ \mathrm{CNT}$ porous network as ultrastable cathode for sodium-ion batteries. Compos Commun 13:97-102

54. Tian JJ, Yang H, Fu CM et al (2020) In-situ synthesis of microspherical Sb@C composite anode with high tap density for lithium/ sodium-ion batteries. Compos Commun 17:177-181

55. Sun YJ, Zheng JF, Yang Y et al (2021) Design advanced porous Polyaniline-PEDOT: PSS composite as high performance cathode for sodium ion batteries. Compos Commun 24:100674

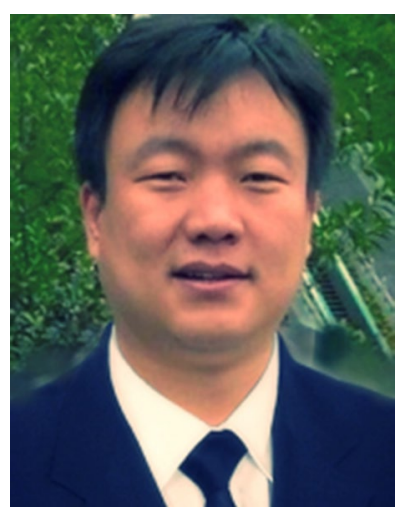

Wei Feng is a professor at the School of Materials Science and Engineering in Tianjin University. He obtained his Ph.D. degree from the Xi'an Jiaotong University in 2000. Then, he worked at Osaka University (Japan) and Tsinghua University (China) as a JSPS fellow and postdoctoral researcher, respectively. In 2004, he became a full professor in Tianjin University, and he has obtained the support of National Science Fund for Distinguished Young Scholars in China. His research interests include photoresponsive organic molecules and their derivatives, thermal-conductive and high-strength carbon-based composites, and 2D fluorinated carbon materials and polymers. 